\title{
5G TechnologyAccess-Research and Vision
}

\author{
Neha ${ }^{1}$, Pooja Gupta ${ }^{2}$ \\ ${ }^{1}$ (Department of Computer Science, Jamia Hamdard, India) \\ ${ }_{2}^{2}$ (Department of Computer Science, Jamia Hamdard, India)
}

\begin{abstract}
The next edge mobile innovation which is relied upon to be propelled by 2020 is named as $5 G$ as it is an overhauled form of the current and building up system 4G, generally known as LTE (Long Term Evolution) network. $5 G$ itself will be equipped for intersection the current benchmarks of speed and network. This paper will take a survey in $5 G$ systems having a wide view about the forthcoming future generation which will be in fact touching the genuine statures. The attention is for the most part on the centre possibilities to be taken in the present media transmission network to shape a dream of 5G. Joining the distinctive advancements which incorporate the innovative work subjects in the related fields are additionally taken care in this paper which covers advances like Nanotechnology, Cloud Computing, Flat IP idea, BDMA and that's only the tip of the iceberg. The paper addresses the different parts of the foundation change for specialist co-ops to overhaul themselves from the correspondence suppliers to the advanced way of life empowering agent. Another approach for the cutting edge remote correspondence and rising logical advancements is additionally canvassed in the same.
\end{abstract}

Keywords:5G,Nanotechnology, Nanocore,Cloud Computing, Flat IP idea, Beam DivisionMultiple Access

\section{Introduction}

Today and in the current future, to satisfy the assumptions and difficulties of the not so distant future, the wireless systems of today should progress in different ways. Late innovation constituent like rapid bundle get to (HSPA) and long haul development (LTE) will be propelled as a section of the advancement of current wireless technologies. In any case, assistant segments may likewise constitute future new remote based innovations, which may aide the advanced advances. Example of these new innovation segments are distinctive methods for getting to range and significantly higher frequency range, the actuation of huge antenna configuration, guide gadget to-gadget correspondence, and ultra-dense deployment [1].Since its introduction in the late 1970s, versatile wireless communication correspondence has run over from simple voice calls to current present day advancements skilled of giving astounding mobile broadband administrations with end-client information rates of a few megabits per second over wide territories and tens, or even hundreds, of megabits per second locally. The broad changes as far as probability of portable correspondence systems, alongside the start of new sorts of cell phones, for example, advanced mobile phones and tablets, have created an emission of new applications which will be utilized as a part of cases for versatile availability and a resultant exponential development in system movement. This paper exhibits our view on the fate of wireless correspondence for 2020 and past. In this paper, we depict the key difficulties that will be experienced by future remote correspondence while powering the organized society[1].The creative ability of our future is an arranged society with unbounded access to data and sharing of information which is available all over the place and each time for everybody and everything. To understand this creative energy, new innovation segments should be inspected for the advancement of existing remote based advances. Display remote based advancements, similar to the third Generation Partnership Project (3GPP) LTE innovation, HSPA and Wi-Fi, will be joining new innovation segments that will be addressing the requirements without bounds. By and by, there might be sure situations that can't be enough tended to alongside the development of progressing existing innovations. The prompting of totally new remote based advances will supplement the present advances which are required for the long haul acknowledgment of the organized society $[2,13]$.

\section{Evolution}

Mobile communication has become more popular in last few decades due to fast revolution in mobile technology. This revolution is because of high increment in telecoms users. This transformation is from 1G-the first generation, 2G-the second generation, 3G-the third generation, and after that the 4G the fourth generation and 5G-the fifth second generation.

\subsection{First Generation(1G)}

$1 \mathrm{G}$ were presented in 1980's and proceeded till 1990. All the systems were analog systems embedded with the frequency modulation technique for radio transmission using frequency division multiple access. It 
enabled it's consumer to make voice calls just inside same nation. There were a few cons of this era like poor voice quality, handoff dependability, and battery life, expansive size of telephones, no security mechanism et cetera.

\subsection{Second Generation(2G)}

The idea of Short Message Services was concocted by 2 G.The utilization of digital signals was presented in this generation and depend on GSM. This versatile innovations utilizes time division various get to (TDMA) or code division numerous get to (CDMA) mechanism. This generation make utilization of CODEC (pressure and multiplex calculation) to pack and multiplex voice data. It can deal with more calls per measure of data transmission opposite $1 \mathrm{G}$ generation. Handsets are typically littler, lighter and more strong. It emanates less radio power. It is more secure for consumers to utilize. The battery life of handsets endures longer as contrasted and $1 \mathrm{G}$. The error checking has enhanced sound quality. There is diminishment in commotion levels. The digital voice encoding has made calls less helpless to roof dropping from outsiders because of utilization of radio scanner.It guarantees quick call set up.It empowers conversing with number of gatherings simultaneously.It empowers to put an approach hold while one gets to another call.It advises one of another call while on a call Encoded discussion or conversation that can't be effectively tapped. It gives capacity to utilize same telephone in number of nations.

\subsection{Third Generation(3G)}

$3 \mathrm{G}$ alludes to third generation mobile transmission. It was built up in 2000 . When contrasted with $1 \mathrm{G}$ and 2G it gives most elevated speed of $144 \mathrm{Kbps}$ to $2 \mathrm{Mbps}$. It is otherwise called Mobile Telecommunication 2000. It has improved voice, information video and remote control technology.it also has ease of use on every mainstream display like mobile phones, messages, pagers, fax, video conferencing and web surfing. Frequency band is 16-25 GHz. Thus mobile technology has both circuit/packet switching.It also have International roaming capability, excellent nature of voice. Its applications includestill photography, video information.

\subsection{Fourth Generation(4G)}

Another packet switched technology is fourth generation with wide territory scope and high throughput. It is intended to be financially savvy and to give high otherworldly effectiveness. It gives the capacity for overall roaming to get to cell anyplace. It has some special technical speciality that support better call control technique, interactive video, voice, streaming video in addition to low cost per bit. Global access High speed, High capacity, better spectral efficiency are some more features of $4 \mathrm{G}$ technique.

\subsection{Fifth Generation(5G)}

Next vision of 2020 in wireless technology is 5th generation which overcome the limitations of $4 \mathrm{G}$ technology.5th generation will be based on Beam division Multiple Access technology. This correspondence innovation blends every improved advantage of cell phones like dialing speed, MP3 recording, cloud capacity and many more. There are extensively two considerations going ahead with $5 \mathrm{G}$ :

a) A Service led view which gives $5 \mathrm{G}$ a high ground more than $2 \mathrm{G}, 3 \mathrm{G}$, 4G, Wi-fi and different developments giving far more prominent scope and dependably on unwavering quality .

b) Second view is driven by a stage change in information speed and request of size lessening in end-to-end inactivity.

A thought to move towards $5 \mathrm{G}$ depends on current floats, it is usually expected that $5 \mathrm{G}$ cell systems must address six difficulties that are not successfully tended to by $4 \mathrm{G}$ i.e. higher limit, higher information rate, bring down End to End latency,massive gadget availability, diminished cost and predictable Quality of Experience provisioning[7][8]. These difficulties are compactly appeared in Fig. 1 alongside some potential facilitators to address them. An overview of the challenges, facilitators, and corresponding design fundamentals for $5 \mathrm{G}$ is shown in Fig 1. 


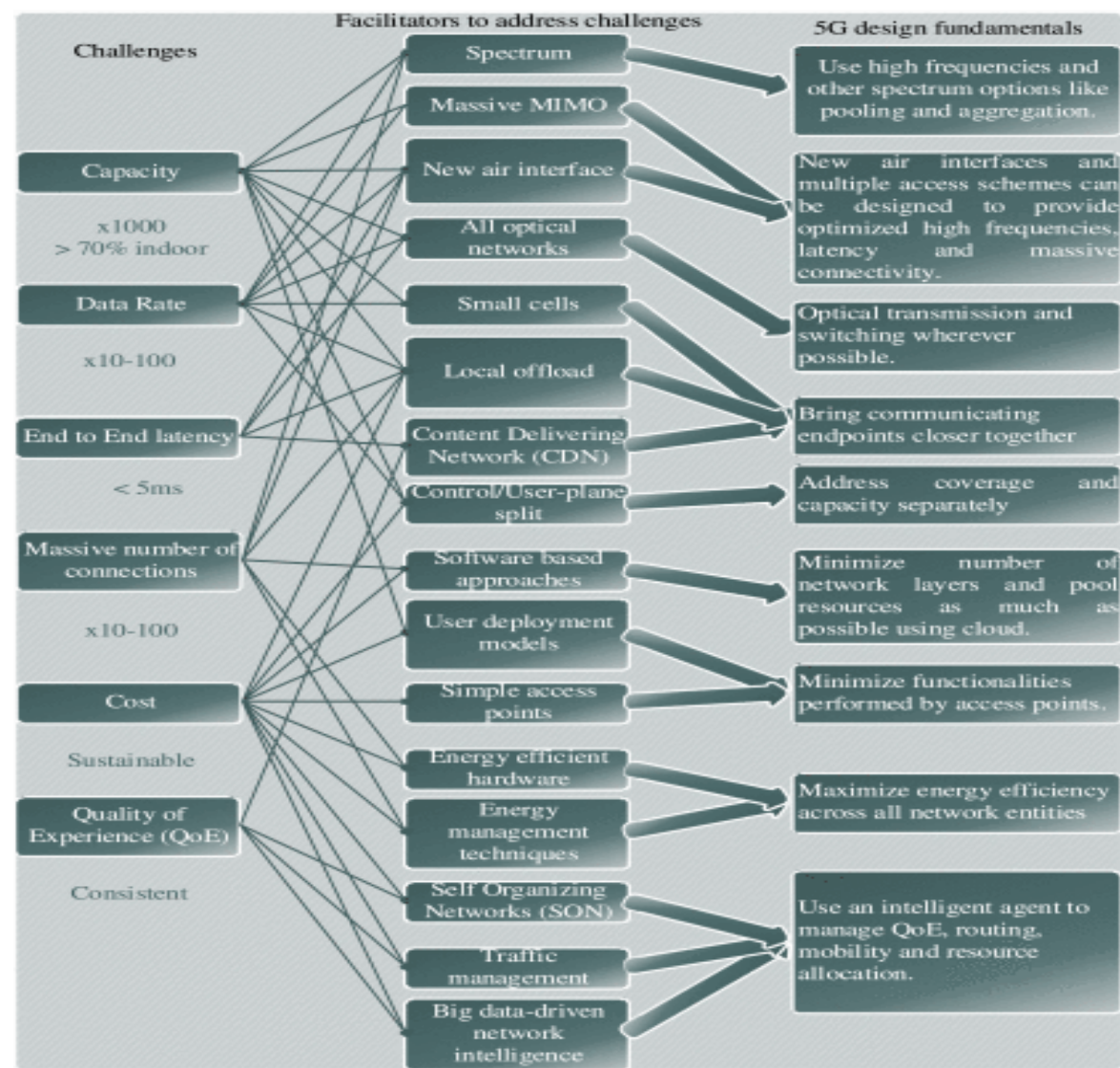

Fig. 1.5G challenge, facilitators, and design fundamental[6,13]

III. Comparison of All mobile technology

Table 1.Technical Comparison recent technologies[2,9,10,13]

\begin{tabular}{|c|c|c|c|c|c|}
\hline $\begin{array}{l}\text { Technology } \\
\text { Features } \perp\end{array}$ & $1 \mathrm{G}$ & $2 \mathrm{G}$ & $3 \mathrm{G}$ & $4 \mathrm{G}$ & $5 \mathrm{G}$ \\
\hline Deployment & $1970-1980$ & $1990-2004$ & $2004-2010$ & At Present & Soon(probably 2020) \\
\hline Signal & Analog & Digital & Digital & Digital & Digital \\
\hline Data Bandwidth & $2 \mathrm{kbps}$ & 64kbps & 2Mbps & $1 \mathrm{Gbps}$ & Higher than $1 \mathrm{Gbps}$ \\
\hline Frequency Band & $800 \mathrm{MHz}$ & $\begin{array}{l}850 / 900 / 1800 / 1 \\
900 \mathrm{MHz}\end{array}$ & $\begin{array}{l}850 / 900 / 1800 / \\
1900 / 2100 \\
\mathrm{MHz}\end{array}$ & $\begin{array}{l}1.8-2.6 \mathrm{GHz}(\mathrm{LTE}) \\
2.3 \mathrm{GHz}, 2.5 \\
\mathrm{GHz}, 3.5 \mathrm{GHz} \\
\text { initially }\end{array}$ & $\begin{array}{l}1.8,2.6 \mathrm{GHz} \text { and } \\
\text { expected } 30-300 \mathrm{GHz}\end{array}$ \\
\hline $\begin{array}{l}\text { Access } \\
\text { Technology }\end{array}$ & $\begin{array}{l}\text { Analog } \\
\text { Cellular } \\
\text { Technology }\end{array}$ & $\begin{array}{l}\text { Digital Cellular } \\
\text { Technology }\end{array}$ & $\begin{array}{l}\text { CDMA } \\
\text { UMTS, EDGE }\end{array}$ & WiMax LTE Wi-Fi & $\begin{array}{l}\text { Beam Division } \\
\text { Multiple Access ,Non } \\
\text { and Quasi orthogonal } \\
\text {,Filter bank multi } \\
\text { carrier }\end{array}$ \\
\hline Multiplexing & FDMA & TDMA,CDMA & $\begin{array}{l}\text { CDMA,OFD } \\
\mathrm{M}\end{array}$ & $\begin{array}{l}\text { CDMA,OFDM/SC- } \\
\text { FDMA }\end{array}$ & CDMA,BDMA \\
\hline IEEE Standards & 802.11 & $802.11 \mathrm{~b}$ & $802.11 \mathrm{~g} / \mathrm{a}$ & $802.11 \mathrm{n}$ & $802.11 \mathrm{ac}$ \\
\hline Switching & Circuit & $\begin{array}{l}\text { Circuit, } \\
\text { Packet }\end{array}$ & $\begin{array}{l}\text { Packet (except } \\
\text { of air } \\
\text { interface) }\end{array}$ & All Packet & All Packet \\
\hline Core Network & PSTN & PSTN & $\begin{array}{l}\text { Packet } \\
\text { Network }\end{array}$ & Internet & Internet \\
\hline $\begin{array}{l}\text { Forward Error } \\
\text { Correction }\end{array}$ & NA & NA & $\begin{array}{l}\text { Turbo codes, } \\
\text { Concatenated } \\
\text { Code (in } \\
3.75 \mathrm{G}) \\
\end{array}$ & Turbo Code & $\begin{array}{l}\text { Low Density Parity } \\
\text { Check Code(LDPC) }\end{array}$ \\
\hline Application & Voice & Voice + Data & $\begin{array}{l}\text { Voice+Data+ } \\
\text { Video Calling } \\
\end{array}$ & $\begin{array}{l}\text { Online Gaming, } \\
\text { High Definition } \\
\text { Television content, }\end{array}$ & $\begin{array}{l}\text { Ultra High Definition } \\
\text { Video +Virtual Reality } \\
\text { Application }\end{array}$ \\
\hline
\end{tabular}




\begin{tabular}{|c|c|c|c|c|c|}
\hline & & & $\begin{array}{l}\text { Online } \\
\text { Gaming + } \\
\text { High } \\
\text { Defination } \\
\text { Television } \\
\end{array}$ & $\begin{array}{l}\text { Digital Video } \\
\text { Broadcasting } \\
\text { (DVB), and video } \\
\text { chat, mobile TV }\end{array}$ & \\
\hline Limitations & $\begin{array}{l}\text { 1. Limited } \\
\text { capacity } \\
2 . \text { Low } \\
\text { calling } \\
\text { capacity } \\
\text { 3. No room } \\
\text { for spectrum } \\
\text { growth } \\
\text { 4. Poor data } \\
\text { communicatio } \\
\text { ns } 5 . \text { Minimal } \\
\text { privacy } \\
6 . \text { Lack of } \\
\text { fraud } \\
\text { protection }\end{array}$ & $\begin{array}{l}\text { 1. Demands } \\
\text { strong digital } \\
\text { signals to assist } \\
\text { connections of } \\
\text { mobile phones } \\
2 \text {. Unable to } \\
\text { hold complex } \\
\text { data such as } \\
\text { videos }\end{array}$ & $\begin{array}{l}\text { 1. Expensive } \\
\text { fees for } 3 \mathrm{G} \\
\text { Licenses } \\
\text { Services } \\
\text { 2. Big size of } \\
\text { mobile phones } \\
\text { 3. Expensive } \\
\text { in nature } \\
\text { 4. Higher } \\
\text { bandwidth } \\
\text { requirements }\end{array}$ & $\begin{array}{l}\text { 1. Expensive and } \\
\text { hard to implement } \\
\text { 2. Battery usage is } \\
\text { more } \\
\text { 3. Needs complex } \\
\text { hardware }\end{array}$ & --------- \\
\hline
\end{tabular}

\section{5G Cellular Network Architecture}

To meet the requests of the user and to beat the difficulties that has been advanced in the $5 \mathrm{G}$ technology, an extraordinary change in the technique of outlining the $5 \mathrm{G}$ remote cell design is required.In present wireless cell design, for a mobile user to convey whether inside or outside, an outside base station show amidst a cell helps in correspondence. So for inside user to speak with the outside base station, the signs should go through the dividers of the inside, and this will bring about high penetration loss, which correspondingly costs with diminished spectral efficiency, information rate, and vitality productivity of wireless communications. To defeat this challenges, another thought or planning strategy that has come into reality for conspiring the 5G cell design is to unmistakable outside and inside setups [4]. With this outlining method, the penetration loss through the walls of the building will be marginally decreased.Since the $5 \mathrm{G}$ cell engineering is heterogeneous, so it must incorporate macrocells, microcells, little cells, and relays[5]. The 5G cell organize design is clarified in [4] and [6]. It has approach significance as far as front end and backhaul arrange individually. In this paper, a general 5G cell arrange design has been proposed as appeared in Fig. 2

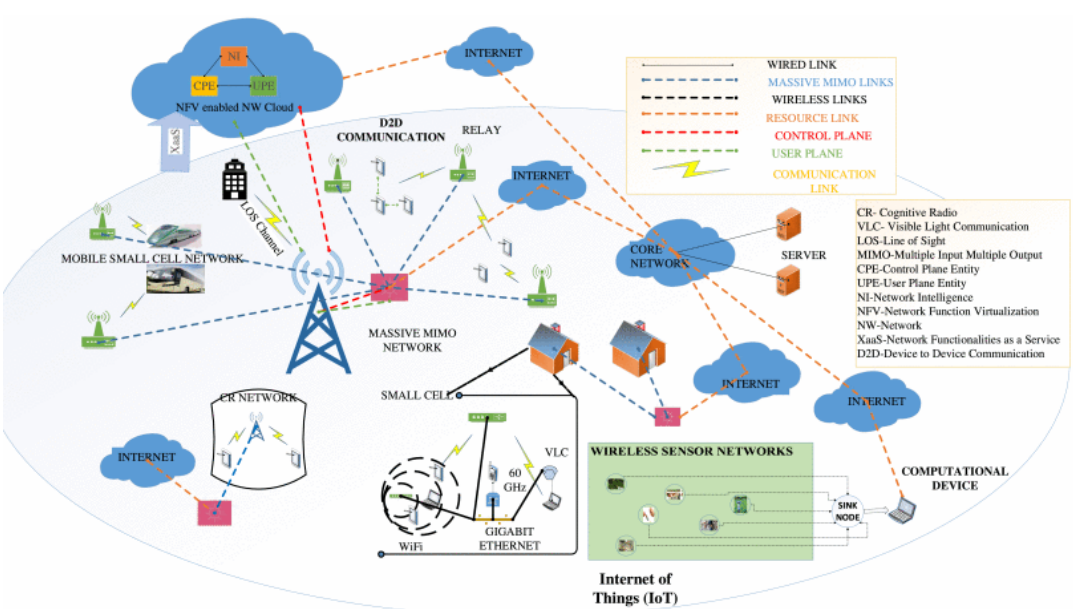

Fig 2.A general 5G cellular network architecture.

In 5G architecture can be designed the Nano Equipment consist of Morph Graphene's Transistor, Liquid lens ,Intelligent Batteries ,Nano sensors . Level IP Network Flat IP engineering gives an approach to recognize gadgets utilizing symbolic names, dissimilar to the various levelled design, for example, that utilized as a part of "normal" IP addresses[11]. The Flat IP network diminish the quantity of system components in the information. In part decouple the cost of conveying administration from the volume of information transmitted. It also limit system latency,the basic architecture consists these areproposed in Fig 3

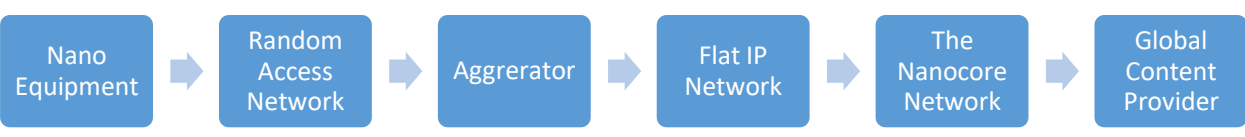

Fig 35 G architecture 


\subsection{Nanocore}

Globalization is the most recent offering of the advanced innovation. Convergence in the innovation is the primary plan of system networks for making it conceivable on account of performing comparable errands. The basic clarification of the digitization is the change of atoms to bits, the digitization of all media content. The words, sounds, pictures, and so on will get changed into digital data and we will have the capacity to grow the potential connections amongst them and consequently empowering them to stream over the stages accessible and recently presented ones

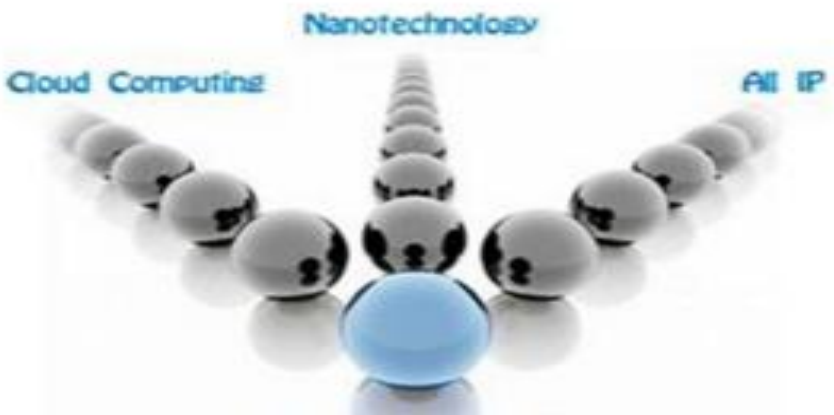

Fig 4.Nanocore

The 5G Nancore is a meeting of underneath specify innovations:

a) Nanotechnology

b) Cloud Computing

c) All IP Platforms

\subsection{Nanotechnology}

This is the application of nano science to make the control process to a nano meter scale which will be in between 0.1 and 100nm. This particular field is known as Molecular Nano Technology.The communication world will drastically get changed into the most recent Nanotechnology in little year time. Putting the effect in both mobile and in addition core network system is the method of operation of the nanotechnology. Flawlessness in security and the better effect on the sensor makes the nanotechnology the most critical in its column. Presentation of the Graphene's transistor is the development to be accomplished [9]. A transistor which is been assembled utilizing the new material by name Graphene, mostly comprises of a type of graphite that comprises of a solitary layer of carbon atmos which has been orchestrated as honeycomb example. The specific structure will help the electrons to go through it rapidly and gives more noteworthy proficiency than the regularly existing handset chip material Mobile phones improved with the carbon nanotube will be presented soon which comes under the nanotechnology. Other primary up and coming functionalities are microscopic microphones, liquid lenses linked with global positioning system satellites connected with worldwide situating satellites are the exceptionally firm and most recent thought of electronic noses and some more. Getting maximally touchy to the sounds we need and in the meantime, insignificantly delicate to the sounds we don't need will be made conceivable by the utilization of numerous amplifiers. This will effectively chop down the capable of being heard commotion via telephone. Liquid Lenses points is the reasonable thought in which the static focal points which we are utilizing these days will be supplanted with Intelligent lenses which will have the sense to stay concentrate on what we are going for and this will adequately clear a path to lessen the jitter.

\subsection{Cloud Computing}

Cloud Computing is an innovation that uses the web and central remote server to keep up information and applications. In $5 \mathrm{G}$ network this central remote server will be our content provider. Cloud Computing enables shoppers and business to utilize applications without establishment and get to their own documents at any PC with web get to[12]. Nanocore a similar idea will be utilized as a part of which the user tries to get to his private record from a worldwide substance provider as cloud. 5G will add on the constant applications through the Nanocore clouding. The Cloud computing has three segments as Application, Platform and Infrastructure shown in Fig 5 


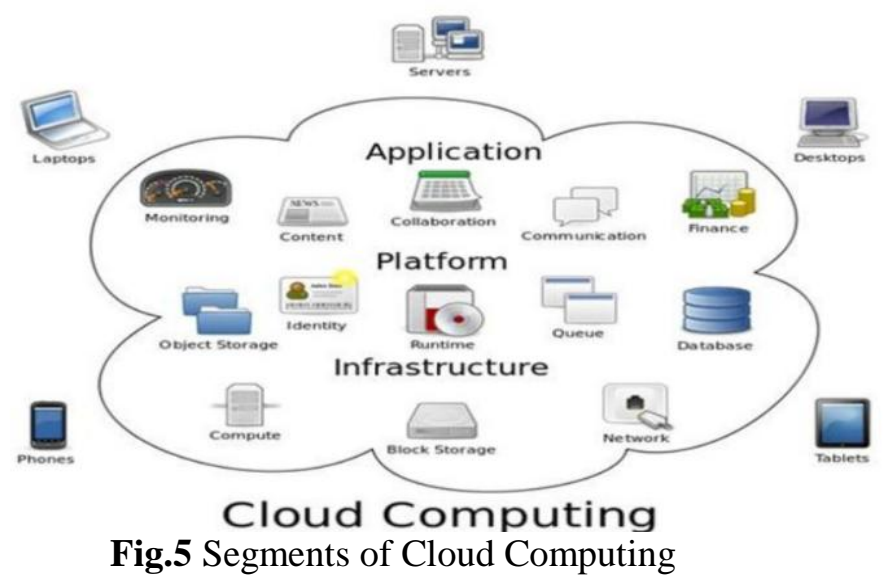

Applications implies, software services on request. They will be fluctuated in valuing plans and the path by which the product is being conveyed to the end user. The items which are utilized to send web is by and large alluded to as the stage fragment of cloud computing. The third and the last section in cloud computing is the foundation and is the foundation of the whole idea. The infrastructure merchants will enable the client to fabricate applications in this platform. Satisfying the client request is achieved in $5 \mathrm{G}$ by the common joining of all the three sections. The CAPEX (Capital Expenditure) of $5 \mathrm{~g}$ has been lessened by the cloud computing sending. Less weight of charging is the arrival benefit for the user.

\subsection{All IP Network}

A typical stage is required to associate for the joining of various innovations to forma single $5 \mathrm{G}$ Nanocore [3]. The fundamental piece of the 5G system will be the Flat IP architecture. So as to meet the expanding necessity of the mobile communication network, All IP Network (AIPN) has been presented by the 3GPP network. Moving into AIPN will meet the prerequisites of the user for the real time information applications conveyed over the mobile broadband systems. Arrangement of the total edge execution as far as both execution and expenses is the essential concentration of the upgraded packet switch innovation. The touched advantages of the IP structures are decrease of the, systemlatency, enhanced user experience, core network evolution, global system advancement, decoupled radio access, cost viability and substantially more. Position of the stringent execution requests on IP based types of equiment and devices, which prompts the developing interest of the multicore innovation. Strong requests have been found in the Next Generation Network (NGN) network both in wired and wireless layers [3]. Another imperative test in the mobile communication field is that the system ought to be such that it ought to be adaptable and enhanced to give bigger number of associations with numerous users without losing the quality inside the constrained recurrence range accessible with the expanded network limit. Communication made conceivable inside restricted spectrum range and time is the greatest test to be handled legitimately with no escape clauses. Meeting this objective is accomplished by the usage of numerous get to systems like OFDMA, FDMA, TDMA,CDMA, and so on. [3].

\section{BEAM DIVISION MULTIPLE ACCESS (BDMA) FOR 5G}

BDMA is the most recent allotment method in which an orthogonal bar is allotted to every mobile station. In this strategy, a receiving antenna bam will get isolated and dispensed into the areas of the mobile stations to give numerous access, accordingly expanding the limit of the system. Since mobile stations and the base stations are in Line of Sight state, they can transmit beams which coordinated to each other's position for legitimate correspondence, without making any sort of obstruction with cell edge mobile stations. At the point when the mobile stations aresituated at various points contrasted with the base station, the base station will transmit the beams such that diverse edges will be secured and in the meantime various mobile stations will be taken care. The working resembles one mobile station does not utilize one beam solely, but rather the mobile stations situated at comparative points will continue sharing the one beam to speak with the base station[14].

Mobile stations that are having a similar beam will isolate a similar recurrence or time assets and will utilize the orthogonal 


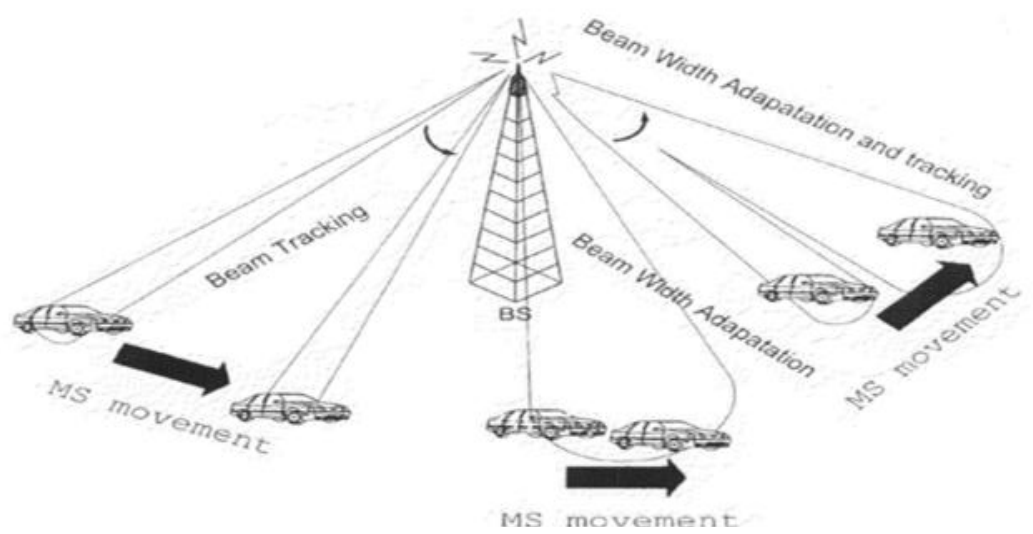

Fig 6 Beam Division Multiple Access

As per the wireless condition, a base station can alter the course, number and separate widths of the beams adaptively with generally effectiveness. Three-dimensional method of division will occur on account of bars and thus a spatial reuse of frequency or time assets can be maximized.The first space of correspondence is the base station and the mobile station does not know each other's position. The mobile station will recognize their positions and the moving velocities and will transmit the whole data to the base station. The second stage is taken care by the base station. The base station will figure the bearing alongside the width of a downlink beam, which depends on the position and moving velocity data gotten from the mobile station. After the computation part is over, the base station will transmit the downlink beam to the mobile station with all calculation regards to the direction and width.

\section{VI . Conclusion}

The future upgrade of Nano core will be unimaginable as it consolidates with Artificial Intelligence (AI). Human life will be encompassed by artificialsensors which could be communicating with your cell phones. We may get a situation where we don't require any range for correspondence. We may have a solitary Nano Core common for every one of the countries. This may enhance portability of user and additionally a littler measure of charging to end user. Everything relies on upon how individual will use these advancements in an inventive way. The advancement of the wireless systems is going towards higher information rates and all-IP standard. Mobile terminals are acquiring every year additionally processing power, more memory on board, and longer battery life for similar applications. 5G incorporate most recent innovations, for example, cognitive radio, SDR, nanotechnology, cloud computing and in light of All IP Platform. It is normal that the underlying Internet theory of keeping the system straightforward as would be prudent, and giving more functionalities to the end hubs, will move toward becoming reality later on generation of mobile systems, here alluded to as $5 \mathrm{G}$.

\section{The accompanying are the elements of $5 \mathrm{G}$ that makes it exceptional system:}

(i) Faster information transferrate as contrasted and last generation.

(ii) Large memory

(iii) Fast dialling speed.

(iv) HD quality picture.

(v) More alluring and more powerful.

(vi) Peak transferring and downloading speed.

(vii) Remote diagnostics.

(viii) Up to $25 \mathrm{Mbps}$ association speed.

(ix) High quality administrations to stay away from errors.

(x) Bi-directional expansive data transmission or large Bandwidth.

\section{References}

[1]. R. Baldemair et al., "Evolving wireless communications: Addressing the challenges and expectations of the future", IEEE Veh. Technol. Mag., vol. 8, pp. Mar. 2013,24-30.

[2]. T. Rappaport, Wireless Communications: Principles and Practice (Englewood Cliffs, NJ, USA: Prentice-Hall, 1996).

[3]. Imthiyaz Ali, "5G the Nanocore" International Journal of Engineering and Innovative Technology (IJEIT), 2(3): 2277-3754, March 5,2011 .

[4]. C.-X. Wang et al., "Cellular architecture and key technologies for 5G wireless communication networks", IEEE Commun. Mag., vol. 52, no. 2, pp. 122-130, Feb. 2014. 
[5]. F. Haider et al., "Spectral efficiency analysis of mobile Femtocell based cellular systems", Proc. IEEE ICCT, pp. 347-351, Sep. 2011.

[6]. P. Agyapong, M. Iwamura, D. Staehle, W. Kiess, A. Benjebbour, "Design considerations for a 5G network architecture", IEEE Commun. Mag., vol. 52, no. 11, pp. 65-75, Nov. 2014.

[7]. M. Fallgren et al., Scenarios Requirements and KPIs for 5G Mobile and Wireless System, Apr. 2013.

[8]. Industry Proposal for a Public Private Partnership (PPP) in Horizon 2020 (Draft Version 2.1) Horizon 2020 Advanced 5G Network Infrastructure for the Future Internet PPP, [online] Available: http://www.networks-etp-eu/fileadmin/user_upload/Home/draft-PPPproposal.pdf.

[9]. T. Halonen, J. Romero, J. Melero, GSM GPRS and EDGE Performance: Evolution Towards 3G/UMTS( New York, NY, USA:Wiley, 2003)

[10]. E. Perahia, C. Cordeiro, M. Park, L. L. Yang, "IEEE 802.11ad: Defining the next generation multi-Gbps Wi-Fi", Proc. 7th IEEE Consum. Commun. Netw. Conf., pp. 1-5, Jan. 2010.

[11]. A. Osseiran et al., "Scenarios for 5G mobile and wireless communications: The vision of the METIS project", IEEE Commun. Mag., vol. 52, no. 5, pp. 26-35, May 2014.

[12]. P. Rost et al., "Cloud technologies for flexible 5G radio access networks", IEEE Commun. Mag., vol. 52, no. 5, pp. 68-76, May 2014.

[13]. A. Gupta; R. K. Jha,"A Survey of 5G Network: Architecture and Emerging Technologies."IEEESpecial Section On Recent Advances In Software Defined Networking For 5g Networks

[14]. Sapana Singh, Pratap Singh. "Key Concepts and Network Architecture for5G Mobile Technology", International Journal of Scientific ResearchEngineering \& Technology (IJSRET). 1(5):165-170, (2012). 